\title{
Prevalence and determinants of chewing khat among women in Ethiopia: data from Ethiopian demographic and health survey 2016
}

Yimenu Yitayih ${ }^{1 *}$ and Jim van Os $2,3,4$

\begin{abstract}
Background: In Ethiopia and other countries in eastern Africa, khat abuse is an increasing public health problem. Levels of use appear to be increasing in women, who are more vulnerable to khat-related problems. However, population-based data are lacking as studies have been small and related to specific settings. This study aimed to contribute to current knowledge on the prevalence of chewing khat and associated factors among women in Ethiopia, using data from the 2016 Ethiopian national demographic and health survey.

Methods: The 2016 EDHS used a two-stage stratified sampling design to select households. A total of 645 enumeration areas (202 urban and 443 rural) were selected, based on the 2007 Ethiopia Population and Housing Census. In these, 18,008 households were considered, from which 15,683 women were included from individual households. The women were interviewed by trained lay interviewers. Data were tabulated and logistic regression was used to examine mutually adjusted associations, expressed as adjusted odds ratios.

Results: The lifetime prevalence of chewing khat among women was $9.9 \%$. Current khat use was $8.4 \%$, with a mean of 14.2 days of use in the last month. Khat use increased with increasing age, remaining constant after age 35 years, having one child, lower educational level, being Muslim by religion and not pertaining to the lowest wealth index category. Not being in a marital relationship with the most recent sex partner and Protestant religion were protective factors.

Conclusion: Lifetime prevalence of chewing khat among women in Ethiopia is substantial and associated with specific sociodemographic risks. These can be used in targeted public health efforts to control the use of khat and reduce the associated health and economic burden.
\end{abstract}

Keywords: Ethiopia, Substance-related disorders, Catha edulis, Khat use, Women's health, Community health

\footnotetext{
* Correspondence: yemenu2007@gmail.com

'Department of Psychiatry, College of Medical faculty, Jimma University, Jimma, Ethiopia

Full list of author information is available at the end of the article
}

(c) The Author(s). 2021 Open Access This article is licensed under a Creative Commons Attribution 4.0 International License, which permits use, sharing, adaptation, distribution and reproduction in any medium or format, as long as you give appropriate credit to the original author(s) and the source, provide a link to the Creative Commons licence, and indicate if changes were made. The images or other third party material in this article are included in the article's Creative Commons licence, unless indicated otherwise in a credit line to the material. If material is not included in the article's Creative Commons licence and your intended use is not permitted by statutory regulation or exceeds the permitted use, you will need to obtain permission directly from the copyright holder. To view a copy of this licence, visit http://creativecommons.org/licenses/by/4.0/. The Creative Commons Public Domain Dedication waiver (http://creativecommons.org/publicdomain/zero/1.0/) applies to the data made available in this article, unless otherwise stated in a credit line to the data. 


\section{Background}

Khat (Catha edulis) is a natural stimulant widely cultivated and available in East Africa and the Middle East [1]. The biochemically active ingredients of khat are cathinone and cathine, which are alkaloid chemicals bearing resemblance to the psychoactive substance of amphetamine, both structurally and functionally [2]. Cathinone is the main psychoactive component of khat leaves and a potent stimulator of the sympathetic nervous system as well as the central nervous system, similar to the pharmacological effects of amphetamine [2]. Chewing fresh leaves of the khat tree is the most common mode of intake [3].

Khat abuse is an increasing public health problem and strongly associated with adverse mental and other outcomes and such as psychological distress, poorer quality of life and increased road traffic accident in low-income countries [4]. Across the world, an estimated 20 million people chew khat leaves daily [4]. Khat is generally used for its perceived ability to facilitate interpersonal communication in social settings, to induce euphoric and performance enhancing effects and to fend off fatigue, as well as for its perceived medicinal value for the treatment of headaches and common cold [5].

Khat use has been associated with numerous health problems. Basic research studies have found evidence of altered stress response [6], cognitive deficits [7, 8], increased levels of depressive symptoms and distress [9] and insomnia [10] in habitual khat users. Research has also shown that prolonged exposure to khat may lead to a long-lasting sensitization to the effects of other drugs [11]. In addition to physical and mental harm, much time and household income is spent on obtaining and chewing khat [12], which severely affects users' social life and family [13]. The habit of chewing khat may be postulated as one of the risky behaviours that could fuel the spread of sexually transmitted infections (STIs) due to associated risky sexual behaviours like having casual sex, unprotected sex and early initiation of sexual activity reported among chewers [14]. Studies reveal that khat consumption may impact fetal health, for example affecting fetal growth by inhibiting utero-placental blood flow $[15,16]$.

Research shows that Khat use is a common practice in Ethiopia [17]. Before 2000, khat chewing by women was generally not considered acceptable [18]. Currently, however, use of khat among women is increasing very rapidly [19]. Research suggests that husbands may be in part responsible for these changes as they encourage their wives to share in the chewing of khat [18].

People who use khat are more vulnerable to khatrelated problems like depressive symptoms, posttraumatic stress disorder and common mental disorder $[20,21]$, the issue to date has not received much attention from local authorities.
Few studies have been conducted to establish prevalence of use and associated factors, and these tended to be small and focusing on specific settings [22].

The current investigation, therefore, aimed to contribute to current knowledge on the use of khat and associated factors among women in Ethiopia, using data from the uniquely representative and population-based 2016 Ethiopian national demo-graphic and health survey (EDHS).

\section{Methods \\ Study design and sampling}

The 2016 EDHS used a two-stage stratified sampling design to select households. In the first stage, there were 645 enumeration areas (202 urban and 443 rural) based on the 2007 Ethiopia Population and Housing Census (PHC). A total of 18,008 households were considered, of which 16,650 households and 15,683 women were eligible. The women were interviewed by trained lay interviewers. All women at reproductive age (15 to 49 years) who were either permanent residents of the selected households or visitors who stayed in the selected household the night before the survey, were eligible for the study. A total of 15,683 women aged 15-49 years were interviewed with a response rate of $95 \%$. The EDHS was designed to provide sociodemographic and health indicators at national (urban and rural) and regional levels. The survey follows an international methodological approach and is conducted at five-year intervals. Detailed methodology is found elsewhere [23].

\section{Measurements}

The dependent variable was chewing khat in the last 30 days. Women who chewed khat in the last month were considered as current khat user. Sociodemographic, socioeconomic and sex-related variables associated with risk were used as independent variables. The independent variables included in this analysis were age, educational status, and marital status.

Household wealth index is based on household ownership of consumer items such as a fan, television, and car. In addition, dwelling characteristics, such as the flooring material; type of drinking water source; and toilet facilities, are among other characteristics related to wealth.

It has five categories: poorest, poorer, middle, richer, and richest), residence, religion, residence, sex of household head (person in the house with main responsibility for making decisions and providing income; can be female regardless of presence of males in the household), number of children, number of sexual partners (if participants were not willing to disclose the information, the variable was coded '9' as a category for 'not known'), sexual transmitted infection (STI) in the last 12 months, relationship to household head, ever reads newspaper or 
magazine (yes/no), ever listens to radio (yes/no), ever watches TV (yes/no), ever use of internet (yes/no), most recent sex partner (if participants indicated they had no sexual partner, this was coded as a separate category; if the participant was not willing to disclose the information, the variable was coded ' 9 ' as a separate category for 'not known').

\section{Statistical data analysis}

The data were extracted, edited, and analysed using SPSS version 23 for Windows. Frequency tables were used to summarize sociodemographic characteristics and prevalence of khat use. Bivariate logistic regression was performed separately for each independent variable. Independent variables with a $p$-value $<0.05$ were entered into the final model for multivariable analysis. Variables in the mutually adjusted multivariable model with a two-sided $p$-value $<0.05$ were considered statistically significant. In order to check for multicollinearity among variables in the multivariable model, variance inflation factors were calculated for all independent variables.

\section{Results}

A total of 15,683 participants were included. The mean

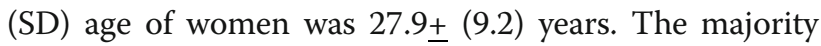
were Orthodox Christian by religion (40.9\%), had no education (44.8\%) and were from rural settings (65.9\%) (Table 1). The highest proportion were from the age group $15-19$ years $(22.3 \%)$ followed by the $20-24$ years group (18.5\%) and the 25-29years group (18.1\%). A total of $24.8 \%$ of participants were identified as 'poorest' and $13 \%$ as 'poorer' according to the wealth index. The mean number of children ever born was 2.6.

The lifetime prevalence of khat chewing among women was $9.9 \%$. The prevalence of current khat chewing was $8.4 \%$, with a mean number of 14.2 days of use in the last month. Highest prevalence of current khat chewing was seen in the age group 40-44 years old (12.9\%), 30-34 years old (12.4\%), 35-39 years old (10.9\%) and 45-49 years old (10.1\%).

Prevalence of current khat chewing was lowest among participants from the lowest wealth index (5.9\%), compared to participants from other wealth index categories. Higher prevalence of current khat chewing was also seen among individuals without education (10.3\%) or only primary education $(8.3 \%)$, compared to those with secondary education (4.9\%) and higher education (4.6\%). Among current khat chewers, the prevalence was highest among those of Muslim religion (18.2\%) as compared to other religious groups $(0.0-2.8 \%)$. The highest prevalence of khat chewing was seen when the relationship to the household head was wife $(10.7 \%)$, and mother (10.7\%), followed by head (9.5\%). Prevalence of current khat use was also higher among respondents who had a single sexual partner (8.6\%), two partners $(8.4 \%)$ and three or more partners (8.2\%), compared to those with no sexual partner (5.4\%). Prevalence of khat use was similar regardless of STI in the last 12 months. The prevalence of current khat use was $8.8 \%$ in urban areas versus $8.2 \%$ in rural areas, and rates were slightly higher among those not reading newspaper/magazines $(8.9 \%$ versus $5.9 \%$ of those reading these), those not listening to radio ( $8.7 \%$ versus $7.8 \%$ of those listening to radio), those not watching TV $(8.5 \%$ versus $8.3 \%$ of those watching), and those without access to internet $(8.6 \%$ versus $6.0 \%$ of those with access).

\section{Multivariable analysis}

Table 2 presents univariable and multivariable models of current khat use. Most predictors contributed in the univariable models. The multivariable model revealed that khat use increased with increasing age until age 35 years, after which it remained more or less constant, having one child (adjusted odds ratio [AOR]: 1.63; 95\% CI, 1.19-2.24), lower educational level (AOR: 2.32; 95\% CI, 1.40-3.87), being Muslim by religion (AOR: 10.48; 95\% CI, 8.41-13.06) and not pertaining to the lowest wealth index category. Protective factors were not being in a marital relationship with the sex partner (AOR: 0.55; 95\% CI, 0.37-0.80) and Protestant religion (AOR: 0.06 ; 95\% CI, 0.01-0.19). There was no evidence of multicollinearity among variables in the multivariable model as the mean variance inflation factor was 1.46 and the highest was 2.66 , i.e. much lower that the 'problematic' range of 5-10.

\section{Discussion}

To the best of our knowledge, this was the first reported study that investigated the prevalence of khat chewing and associated factors among women in the Ethiopian population using the latest nationally representative data obtained from EDHS 2016. The findings reveal that in women, the life time prevalence of khat chewing is $9.9 \%$ versus $8.4 \%$ of current use. Multivariable analysis revealed that current use was more prevalent with higher age, having one child, lower educational level, being Muslim by religion and not pertaining to the lowest wealth index category. Protective factors were not being in marital relationship with sex partner and Protestant religion.

The prevalence of current khat use among women in this study, at $8.4 \%$, was lower as the rate reported in Yemen (29.6\%) [18]. Cultural factors underlying use may differ between the two countries, but differences may also be due to variation in survey design, and other methodological issues.

The multivariable model revealed that khat use increased with age until age 35 years, after which it 
Table 1 Characteristic of the study participants of khat chewing among women in Ethiopia

\begin{tabular}{|c|c|c|c|c|c|c|c|}
\hline \multirow[t]{3}{*}{ Variables } & & \multicolumn{2}{|l|}{ Total } & \multicolumn{4}{|c|}{ Current khat chewing } \\
\hline & & \multirow[t]{2}{*}{$\mathbf{n}$} & \multirow[t]{2}{*}{$\%$} & \multicolumn{2}{|l|}{ No } & \multicolumn{2}{|l|}{ Yes } \\
\hline & & & & $\mathrm{N}$ & $\%$ & $\mathbf{n}$ & $\%$ \\
\hline \multirow[t]{7}{*}{ Age group in years } & $15-19$ & 3498 & 22.3 & 3375 & 96.5 & 123 & 3.5 \\
\hline & $20-24$ & 2903 & 18.5 & 2717 & 93.6 & 186 & 6.4 \\
\hline & $25-29$ & 2845 & 18.1 & 2586 & 90.9 & 259 & 9.1 \\
\hline & $30-34$ & 2241 & 14.3 & 1964 & 87.6 & 277 & 12.4 \\
\hline & $35-39$ & 1917 & 12.2 & 1708 & 89.1 & 209 & 10.9 \\
\hline & $40-44$ & 1302 & 8.3 & 1134 & 87.1 & 168 & 12.9 \\
\hline & $45-49$ & 977 & 6.2 & 878 & 89.9 & 99 & 10.1 \\
\hline \multirow[t]{6}{*}{ Religion } & Orthodox & 6413 & 40.9 & 6231 & 97.2 & 182 & 2.8 \\
\hline & Catholic & 91 & 0.6 & 89 & 97.8 & 2 & 2.2 \\
\hline & Protestant & 2814 & 17.9 & 2810 & 99.9 & 4 & 0.1 \\
\hline & Muslim & 6209 & 39.6 & 5078 & 81.8 & 1131 & 18.2 \\
\hline & Traditional & 84 & 0.5 & 82 & 97.6 & 2 & 2.4 \\
\hline & Other & 72 & 0.5 & 72 & 100 & 0 & 0 \\
\hline \multirow[t]{4}{*}{ Educational level } & No education & 7033 & 44.8 & 6310 & 89.7 & 723 & 10.3 \\
\hline & Primary & 5213 & 33.2 & 4780 & 91.7 & 433 & 8.3 \\
\hline & Secondary & 2238 & 14.3 & 2128 & 95.1 & 110 & 4.9 \\
\hline & Higher & 1199 & 7.7 & 1144 & 95.4 & 55 & 4.6 \\
\hline \multirow[t]{2}{*}{ Residence } & Urban & 5348 & 34.1 & 4876 & 91.2 & 472 & 8.8 \\
\hline & Rural & 10,335 & 65.9 & 9486 & 91.8 & 849 & 8.2 \\
\hline \multirow[t]{2}{*}{ Household head } & Male & 10,853 & 69.2 & 9901 & 91.2 & 952 & 8.8 \\
\hline & Female & 4830 & 30.8 & 4461 & 92.4 & 369 & 7.6 \\
\hline \multirow[t]{8}{*}{ Relationship to household head } & Head & 2803 & 17.9 & 2536 & 90.5 & 267 & 9.5 \\
\hline & Wife & 7413 & 47.3 & 6618 & 89.3 & 795 & 10.7 \\
\hline & Daughter & 3761 & 24.0 & 3582 & 95.2 & 179 & 4.8 \\
\hline & Grand daughter & 178 & 1.1 & 174 & 97.8 & 4 & 2.2 \\
\hline & Mother & 28 & 0.2 & 25 & 89.3 & 3 & 10.7 \\
\hline & Sister & 366 & 2.3 & 345 & 94.3 & 21 & 5.7 \\
\hline & Other relative & 621 & 3.9 & 595 & 95.8 & 26 & 4.2 \\
\hline & Not relative & 513 & 3.3 & 487 & 94.9 & 26 & 5.1 \\
\hline \multirow[t]{2}{*}{ Reads newspaper/magazine } & No & 13,106 & 83.6 & 11,936 & 91.1 & 1170 & 8.9 \\
\hline & Yes & 2577 & 16.4 & 2426 & 94.1 & 151 & 5.9 \\
\hline \multirow[t]{2}{*}{ Listens to radio } & No & 10,338 & 65.9 & 9433 & 91.3 & 905 & 8.7 \\
\hline & Yes & 5345 & 34.1 & 4929 & 92.2 & 416 & 7.8 \\
\hline \multirow[t]{2}{*}{ Watches TV } & No & 10,084 & 64.3 & 9226 & 91.5 & 858 & 8.5 \\
\hline & Yes & 5599 & 35.7 & 5136 & 91.7 & 463 & 8.3 \\
\hline \multirow[t]{2}{*}{ Uses internet } & No & 14,329 & 91.4 & 13,089 & 91.4 & 1240 & 8.6 \\
\hline & Yes & 1354 & 8.6 & 1273 & 94.0 & 81 & 6.0 \\
\hline \multirow[t]{5}{*}{ Wealth index } & Poorest & 3874 & 24.8 & 3664 & 94.1 & 230 & 5.9 \\
\hline & Poorer & 2046 & 13.0 & 1804 & 88.2 & 242 & 11.8 \\
\hline & Middle & 2002 & 12.8 & 1807 & 90.3 & 195 & 9.7 \\
\hline & Richer & 2042 & 13.0 & 1893 & 92.7 & 149 & 7.3 \\
\hline & Richest & 5699 & 36.3 & 5194 & 91.1 & 505 & 8.9 \\
\hline
\end{tabular}


Table 1 Characteristic of the study participants of khat chewing among women in Ethiopia (Continued)

\begin{tabular}{|c|c|c|c|c|c|c|c|}
\hline \multirow[t]{3}{*}{ Variables } & & \multicolumn{2}{|l|}{ Total } & \multicolumn{4}{|c|}{ Current khat chewing } \\
\hline & & \multirow[t]{2}{*}{$n$} & \multirow[t]{2}{*}{$\%$} & \multicolumn{2}{|l|}{ No } & \multicolumn{2}{|l|}{ Yes } \\
\hline & & & & $\mathbf{N}$ & $\%$ & $\mathbf{n}$ & $\%$ \\
\hline \multirow{2}{*}{$\begin{array}{l}\text { Any STI last } \\
12 \text { months }\end{array}$} & No & 15,600 & 99.5 & 14,286 & 91.6 & 1314 & 8.4 \\
\hline & Yes & 83 & 0.5 & 76 & 91.6 & 7 & 8.4 \\
\hline \multirow[t]{4}{*}{ Children } & None & 5409 & 34.5 & 5167 & 95.5 & 242 & 4.5 \\
\hline & 1 & 1974 & 12.6 & 1811 & 91.7 & 163 & 8.3 \\
\hline & 2 & 1704 & 10.9 & 1549 & 90.9 & 155 & 9.1 \\
\hline & $\geq 3$ & 6596 & 42.0 & 5835 & 88.5 & 761 & 11.5 \\
\hline \multirow[t]{5}{*}{ Number of sexual partner } & None & 1282 & 8.2 & 1213 & 94.6 & 69 & 5.4 \\
\hline & 1 & 9178 & 58.5 & 8387 & 91.4 & 791 & 8.6 \\
\hline & 2 & 2207 & 14.1 & 2021 & 91.6 & 186 & 8.4 \\
\hline & $\geq 3$ & 577 & 3.7 & 530 & 91.8 & 47 & 8.2 \\
\hline & Not known & 2439 & 15.5 & 2211 & 90.7 & 228 & 9.3 \\
\hline \multirow[t]{4}{*}{ Most recent sex partner } & Spouse & 9203 & 58.7 & 8396 & 91.2 & 807 & 8.8 \\
\hline & Other & 691 & 4.4 & 657 & 95.1 & 34 & 4.9 \\
\hline & No partner & 162 & 1.0 & 151 & 93.2 & 11 & 6.8 \\
\hline & Not known & 5627 & 35.9 & 5158 & 91.7 & 469 & 8.3 \\
\hline \multirow[t]{2}{*}{ Life time khat use } & No & 14,130 & 90.1 & - & - & - & - \\
\hline & Yes & 1553 & 9.9 & - & - & - & - \\
\hline \multirow[t]{2}{*}{ Current khat chewing } & No & 14,366 & 91.6 & - & - & - & - \\
\hline & Yes & 1317 & 8.4 & - & - & - & - \\
\hline
\end{tabular}

*STI Sexual transmitted infection;

remained approximately constant. This is consistent with a study conducted in eastern Ethiopia [24]. The possible reason may be that as age increases, women are more likely to have alterations in life circumstances such as bereavement, social isolation, lack of social support and financial difficulties, all of which have been found to increase the risk of substance use [25, 26]. It has also been observed that depressive symptoms may increase during the transitional phase from peri-menopause to post-menopause [27, 28], possibly driving selfmedication strategies. Another reason may be that younger women tend to be more under family control, which likely reduces risk of exposure.

Not pertaining to the lowest wealth index category was associated with higher khat use rates. One obvious reason is that buying khat requires a certain level of income [29]. Furthermore, chewing khat is often developed as part of doing business in higher income groups [13]. Also, khat chewing practices affect the economic status of society due to the fact that collectively, it contributes to the loss of thousands of acres of arable land and billions of hours of work as well as utilization of scarce resources to buy khat rather than acquiring nutritious foods and care for household members [30].
Those pertaining to the religion of Islam were at higher odds to chew khat as compared to those of Orthodox religion. This is consistent with earlier work in Ethiopia [31, 32]. Chewing khat is a common practice and traditionally accepted in Islamic communities, associated with perceived benefits in concentration during work and prayer time $[33,34]$.

Women with lower educational status had more risk of current khat chewing compared to women with higher educational status. The current study was in agreement with a study conducted in the Jazan region, in Saudi Arabia, which showed that illiteracy was associated with higher odds of chewing khat [35]. A possible reason is that a lower level of education is associated with lack of knowledge about the negative consequences of khat use [35].

Furthermore, women who had one child had higher odds of khat chewing as compared to women without children. A possible reason is joint use under the influence of a stable partner using khat. However, this would then only apply to the period of the first child, as women with more children again had reduced risk for chewing khat. One explanation is that with an increasing number of children, less resources would be available for the khat habit. 
Table 2 Logistic regression analysis of factors associated with khat chewing among women in Ethiopia, Ethiopia Demographic and Health Survey (EDHS), $2016(N=15,683)$

\begin{tabular}{|c|c|c|c|c|c|c|c|}
\hline Variable & & COR & $95 \% \mathrm{Cl}$ & $P$-value & aOR & $95 \% \mathrm{Cl}$ & $P$-value \\
\hline \multirow[t]{7}{*}{ Age group in years } & $15-19$ & Ref & & & & & \\
\hline & $20-24$ & 1.87 & $1.48-2.37$ & $<0.001$ & 1.84 & $1.30-2.60$ & $<0.001^{*}$ \\
\hline & $25-29$ & 2.74 & $2.20-3.42$ & $<0.001$ & 2.53 & $1.75-3.64$ & $<0.001^{*}$ \\
\hline & $30-34$ & 3.87 & $3.10-4.82$ & $<0.001$ & 4.28 & $2.91-6.30$ & $<0.001^{*}$ \\
\hline & $35-39$ & 3.35 & $2.66-4.22$ & $<0.001$ & 3.47 & $2.30-5.24$ & $<0.001^{*}$ \\
\hline & $40-44$ & 4.06 & $3.19-5.17$ & $<0.001$ & 5.27 & $3.45-8.06$ & $<0.001^{*}$ \\
\hline & $45-49$ & 3.09 & $2.35-4.07$ & $<0.001$ & 3.48 & $2.19-5.53$ & $<0.001^{*}$ \\
\hline \multirow[t]{4}{*}{ Religion } & Orthodox & Ref & & & & & \\
\hline & Protestant $^{\mathrm{a}}$ & 0.07 & $0.03-0.15$ & $<0.001$ & 0.06 & $0.01-0.19$ & $<0.001^{*}$ \\
\hline & Muslim & 7.63 & $6.49-8.95$ & $<0.001$ & 10.48 & $8.41-13.06$ & $<0.001^{*}$ \\
\hline & Traditional & 0.83 & $0.20-3.42$ & 0.80 & 2.41 & $0.56-10.30$ & 0.234 \\
\hline \multirow[t]{4}{*}{ Educational level } & No education & 2.38 & $1.79-3.15$ & $<0.001$ & 1.63 & $0.96-2.77$ & 0.068 \\
\hline & Primary & 1.88 & $1.41-2.51$ & $<0.001$ & 2.32 & $1.40-3.87$ & $0.001^{*}$ \\
\hline & Secondary & 1.07 & $0.77-1.49$ & 1.47 & 1.49 & $0.89-2.50$ & 0.125 \\
\hline & Higher & Ref & & & & & \\
\hline \multirow[t]{5}{*}{ Wealth index } & Poorest & Ref & & & & & \\
\hline & Poorer & 2.13 & $1.76-2.57$ & $<0.001$ & 2.87 & $2.23-3.68$ & $<0.001^{*}$ \\
\hline & Middle & 1.71 & $1.40-2.09$ & $<0.001$ & 2.38 & $1.82-3.11$ & $<0.001^{*}$ \\
\hline & Richer & 1.25 & $1.01-1.55$ & 0.04 & 1.92 & $1.43-2.57$ & $<0.001^{*}$ \\
\hline & Richest & 1.54 & $1.32-1.82$ & $<0.001$ & 2.85 & $2.23-3.65$ & $<0.001^{*}$ \\
\hline \multirow[t]{2}{*}{ Residence } & Urban & Ref & & & & & \\
\hline & Rural & 0.92 & $0.82-1.04$ & 0.192 & & & \\
\hline \multirow[t]{2}{*}{ Household head } & Male & Ref & & & & & \\
\hline & Female & 0.86 & $0.75-0.97$ & 0.02 & 0.96 & $0.68-1.36$ & 0.832 \\
\hline \multirow[t]{4}{*}{ Children } & None & Ref & & & & & \\
\hline & 1 & 1.92 & $1.56-2.36$ & $<0.001$ & 1.63 & $1.19-2.24$ & $0.002^{*}$ \\
\hline & 2 & 2.13 & $1.73-2.63$ & $<0.001$ & 1.34 & $0.94-1.90$ & 0.098 \\
\hline & $\geq 3$ & 2.78 & $2.39-3.23$ & $<0.001$ & 1.14 & $0.81-1.61$ & 0.430 \\
\hline \multirow[t]{5}{*}{ Number of sexual partners } & None & Ref & & & & & \\
\hline & 1 & 1.65 & $1.28-2.13$ & $<0.001$ & 0.74 & $0.55-1.01$ & 0.060 \\
\hline & 2 & 1.62 & $1.21-2.15$ & 0.001 & 1.02 & $0.83-1.25$ & 0.842 \\
\hline & $\geq 3$ & 1.55 & $1.06-2.28$ & 0.024 & 1.11 & $0.75-1.63$ & 0.591 \\
\hline & Not known & 1.81 & $1.37-2.39$ & $<0.001$ & 0.63 & $0.45-0.90$ & 0.010 \\
\hline \multirow[t]{2}{*}{ STI last 12 months } & No & Ref & & & & & \\
\hline & Yes & 1.00 & $0.46-2.17$ & 1.00 & 0.82 & $0.35-1.96$ & 0.670 \\
\hline \multirow[t]{8}{*}{ Relationship to household head } & Head & Ref & & & & & \\
\hline & Wife & 1.14 & $0.98-1.32$ & 0.077 & 1.27 & $0.85-1.90$ & 0.239 \\
\hline & Daughter & 0.47 & $0.39-0.57$ & $<0.001$ & 0.97 & $0.66-1.41$ & 0.885 \\
\hline & Grand daughter & 0.21 & $0.08-0.59$ & 0.003 & 0.51 & $0.11-2.25$ & 0.381 \\
\hline & Mother & 1.13 & $0.34-3.80$ & 0.831 & 2.72 & $0.69-10.75$ & 0.152 \\
\hline & Sister & 0.57 & $0.36-0.91$ & 0.019 & 0.87 & $0.44-1.73$ & 0.707 \\
\hline & Other relative & 0.41 & $0.27-0.62$ & $<0.001$ & 0.91 & $0.50-1.62$ & 0.752 \\
\hline & Not relative & 0.50 & $0.33-0.76$ & 0.001 & 0.92 & $0.49-1.73$ & 0.806 \\
\hline
\end{tabular}


Table 2 Logistic regression analysis of factors associated with khat chewing among women in Ethiopia, Ethiopia Demographic and Health Survey (EDHS), 2016 ( $N=15,683)$ (Continued)

\begin{tabular}{|c|c|c|c|c|c|c|c|}
\hline Variable & & COR & $95 \% \mathrm{Cl}$ & $P$-value & aOR & $95 \% \mathrm{Cl}$ & $P$-value \\
\hline \multirow[t]{2}{*}{ Reads newspaper or magazine } & No & Ref & & & & & \\
\hline & Yes & 0.63 & $0.53-0.75$ & $<0.001$ & 0.91 & $0.68-1.23$ & 0.570 \\
\hline \multirow[t]{2}{*}{ Listens to radio } & No & Ref & & & & & \\
\hline & Yes & 0.87 & $0.77-0.99$ & 0.038 & 1.16 & $0.96-1.40$ & 0.103 \\
\hline \multirow[t]{2}{*}{ Watches TV } & No & Ref & & & & & \\
\hline & Yes & 0.96 & $0.86-1.09$ & 0.605 & & & \\
\hline \multirow[t]{2}{*}{ Use of internet } & No & Ref & & & & & \\
\hline & Yes & 0.67 & $0.53-0.84$ & 0.001 & 1.21 & $0.81-1.81$ & 0.332 \\
\hline \multirow[t]{4}{*}{ Most recent sex partner } & Spouse & Ref & & & & & \\
\hline & Other & 0.53 & $0.37-0.76$ & 0.001 & 0.55 & $0.37-0.80$ & $0.002 *$ \\
\hline & No partner & 0.76 & $0.41-1.40$ & 0.378 & 0.79 & $0.37-1.70$ & 0.551 \\
\hline & Not known & 0.94 & $0.84-1.06$ & 0.360 & 0.97 & $0.81-1.17$ & 0.781 \\
\hline
\end{tabular}

cOR Crude odds ratio, $a O R$ Adjusted odds ratio, ${ }^{*} P<0.05$, STI Sexually transmitted infection

ancludes small group of Catholics

Given that khat use among women is prevalent, and with a mean number of 14.2 days of use in the last month, information campaigns are required in order to inform the public about harmful effect of khat use [36]. For those who are affected by khat use-related disorder and comorbid conditions, treatment services should be provided. Addiction services can be offered using the existing health system. For example, primary health care may introduce routine screening and treatment for substance use [36, 37].

However, given that the majority of people do not have access to good quality of care; it is a timely need for the sustainable programs [38]. Therefore, it is a timely need for pertinent stakeholders of the Ethiopian public health care system to introduce novel approaches to generate financially sustainable programs for the early diagnosis, treatment and control of addiction through a group of well-trained health care providers.

\section{Limitations}

The results should be interpreted in the light of several limitation. First, this was a secondary data analysis which overlooked key variables that are relevant for khat use such as availability, affordability, family substance use and awareness of health consequences of khat use. Second, we cannot exclude social desirability-related underreporting of khat use behaviour, given that female khat use is still associated with a degree of stigma in Ethiopian society.

\section{Conclusion}

In conclusion, the lifetime rate of chewing khat among women in Ethiopia is substantial and associated with specific sociodemographic risks. These can be used in targeted public health efforts to control increasing levels of khat use among women and reduce the associated health and economic burden.

\section{Abbreviations}

AOR: Adjusted odds ratio; CDC: Centers for Disease Control and Prevention: EDHS: Ethiopian national demo-graphic and health survey; STIS: Sexually transmitted infections; PHC: Population and Housing Census

\section{Acknowledgements}

We gratefully acknowledge the participants in the study, the field workers and all governmental and non-governmental institutions which provided support for this project.

\section{Authors' contributions}

YY was involved in the data analysis, interpretation, and manuscript writing JVO was involved in the analysis of the data, the interpretation of the findings and manuscript writing. The authors read and approved the final manuscript.

\section{Funding}

There was no external funding for this study.

Availability of data and materials

The datasets generated and analyzed during the current study will be available in the public repository.

\section{Declarations}

\section{Ethics approval and consent to participate}

The original DHS data were collected in conformity with international and national ethical guidelines. Ethical clearance for the original survey was provided by the Ethiopian Public Health Institute Review Board, the National Research Ethics Review Committee (NRERC) at the Ministry of Science and Technology, the Institutional Review Board of ICF International and the Centers for Disease Control and Prevention (CDC). Informed written consent was obtained from each participant. The data for the present study were downloaded and analyzed after the purpose of the analysis was communicated to and approved by the Demographic and Health Survey Program (Rockville, Maryland, USA).

Consent for publication

Not applicable.

\section{Competing interests}

The authors declare that there was no financial or non-financial conflict of interest. 


\section{Author details}

1 Department of Psychiatry, College of Medical faculty, Jimma University, Jimma, Ethiopia. ${ }^{2}$ Department of Psychiatry, UMC Utrecht Brain Center, University Medical Center Utrecht, Utrecht University, Utrecht, The Netherlands. ${ }^{3}$ Department of Psychiatry and Neuropsychology, School for Mental Health and Neuroscience, Maastricht University Medical Centre, Maastricht, the Netherlands. ${ }^{4}$ Department of Psychosis Studies, Institute of Psychiatry, Psychology \& Neuroscience, King's College London, London, UK.

Received: 13 April 2020 Accepted: 23 February 2021

Published online: 04 March 2021

\section{References}

1. Belew M, Kebede D, Kassaye M, Enquoselassie F. The magnitude of khat use and its association with health, nutrition and socio-economic status. Ethiop Med J. 2000;38(1):11-26.

2. Szendrei K. The chemistry of khat. Bull Narc. 1980;32(3):5-35.

3. Hoffman R, Al'Absi M. Khat use and neurobehavioral functions: suggestions for future studies. J Ethnopharmacol. 2010;132(3):554-63.

4. Eckersley W, Salmon R, Gebru M. Khat, driver impairment and road traffic injuries: a view from Ethiopia. Bull World Health Organ. 2010;88:235-6.

5. Wabe NT. Chemistry, pharmacology, and toxicology of khat (catha edulis forsk): a review. Addict Health. 2011;3(3-4):137.

6. Al Absi M, Khalil NS, Al Habori M, Hoffman R, Fujiwara K, Wittmers L. Effects of chronic khat use on cardiovascular, adrenocortical, and psychological responses to stress in men and women. Am J Addict. 2013:22(2):99-107.

7. Hoffman R, Al' Absi M. Working memory and speed of information processing in chronic khat users: preliminary findings. Eur Addict Res. 2013; 19(1):1-6.

8. Nakajima M, Hoffman R, Al' Absi M. Poor working memory and reduced blood pressure levels in concurrent users of khat and tobacco. Nicotine Tob Res. 2013;16(3):279-87

9. Nakajima M, Jebena MG, Taha M, Tesfaye M, Gudina E, Lemieux A, et al. Correlates of khat use during pregnancy: a cross-sectional study. Addict Behav. 2017;73:178-84.

10. Nakajima M, Dokam A, Kasim AN, Alsoofi M, Khalil NS, Al Absi M. Habitual khat and concurrent khat and tobacco use are associated with subjective sleep quality. Prev Chronic Dis. 2014;11:E86.

11. Banjaw MY, Schmidt WJ. Behavioural sensitisation following repeated intermittent oral administration of Catha edulis in rats. Behav Brain Res. 2005;156:181-9.

12. Milanovic B. Qat expenditures in Yemen and Djibouti: an empirical analysis. J Afr Econ. 2008;17(5):661-87.

13. Aden A, Dimba EA, Ndolo UM, Chindia ML. Socio-economic effects of khat chewing in north eastern Kenya. East Afr Med J. 2006;83(3):69-73.

14. Abebe D, Debella A, Dejene A, Degefa A, Abebe A, Urga K, et al. Khat chewing habit as a possible risk behaviour for HIV infection: a case-control study. Ethiop J Health Dev. 2005:19(3):174-81.

15. Khawaja M, Al-Nsour M, Saad G. Khat (Catha edulis) chewing during pregnancy in Yemen: findings from a national population survey. Matern Child Health J. 2008;12:308-12. https://doi.org/10.1007/s10995-007-0231-2.

16. Mwenda JM, Arimi MM, Kyama MC, Langat DK. Effect of khat (Catha edulis) consumption on reproductive function: a review. East Afr Med J. 2003;80(6): 262-7.

17. Haile D, Lakew Y. Khat chewing practice and associated factors among adults in Ethiopia: further analysis using the 2011 demographic and health survey. PLoS One. 2015;10(6):e0130460.

18. Al-Abed AA, Sutan R, Al-Dubai SA, Aljunid SM. Family context and Khat chewing among adult Yemeni women: a cross-sectional study. BioMed Res Int. 2014;2014:505474.

19. Kandela P. Sana'a women's rights, a tourist boom, and the power of khat in Yemen. Lancet. 2000;355(9213):1437.

20. Al Bahhawi T, Albasheer OB, Makeen AM, Arishi AM, Hakami OM, Maashi SM, et al. Depression, anxiety, and stress and their association with khat use: a cross-sectional study among Jazan University students, Saudi Arabia. Neuropsychiatr Dis Treat. 2018;14:2755.

21. Widmann M, Warsame AH, Mikulica J, von Beust J, Isse MM, Ndetei D, et al. Khat use, PTSD and psychotic symptoms among Somali refugees in Nairobi-a pilot study. Front Public Health. 2014;2:71.

22. Mekuriaw B, Belayneh Z, Yitayih Y. Magnitude of Khat use and associated factors among women attending antenatal care in Gedeo zone health centers, southern Ethiopia: a facility based cross sectional study. BMC Public Health. 2020;20(1):110

23. EDHS E. Demographic and health survey 2016: key indicators report. DHS Program ICF. 2016;363:364.

24. Reda AA, Moges A, Biadgilign S, Wondmagegn BY. Prevalence and determinants of Khat (Catha edu-lis) chewing among high school students in eastern Ethiopia: a cross-sectional study. PLoS One. 2012;7(3):e33946. https://doi.org/10.1371/journal.pone.0033946PMID:22479484.

25. Simoni-Wastila L, Yang HK. Psychoactive drug abuse in older adults. Am J Geriatr Pharmacother. 2006:4(4):380-94.

26. Ziegler PP. Addiction in older women: American health care's best-kept secret. J Calif Dent Assoc. 2008;36(2):115-8.

27. Hunter M. The south-East England longitudinal study of the climacteric and postmenopause. Maturitas. 1992;14:117-26 [PubMed] [Google Scholar].

28. Maartens LWF, Knottnerus JA, Pop VJ. Menopausal transition and increased depressive symptomatology. A community based prospective study. Maturitas. 2002;42:195-200 [PubMed] [Google Scholar].

29. Mulugeta Y. Khat chewing and its associated factor among college students in Bahir Dar town, Ethio-pia. Sci J Publ Health. 2013;1(5):209-14.

30. Ageely HM. Health and socio-economic hazards associated with khat consumption. J Fam Community Med. 2008;15(1):3.

31. Alem A, Kebede D, Kullgren G. The prevalence and socio-demographic correlates of khat chewing inButajira, Ethiopia. Acta Psychiatr Scand. 1999; 397:84-91 PMID:10470360.

32. Zeleke A, Awoke W, Gebeyehu E, Ambaw F. Khat chewing practice and its perceived health effectsamong communities of Dera Woreda, Amhara region, Ethiopia. Open J Epidemiol. 2013;3:160-8.

33. Gebissa E. Leaf of Allah: Khat and agricultural transformation in Harerge, Ethiopia 875-1991. Oxford: James Currey Ltd; 2004

34. Armstrong E. Research note. Crime, chemicals and culture: on the complexity of Khat. J Drug Issues. 2008;38(2):631-48.

35. Alsanosy RM, Mahfouz MS, Gaffar AM. Khat chewing habit among school students of Jazan region, Saudi Arabia. PLoS One. 2013:8(6):e65504.

36. Ahmed S, Minami H, Rasmussen A. A systematic review of treatments for problematic Khat use. Subst Use Misuse. 2020;55(4):590-601.

37. World Health Organization. Integrating mental health into primary care: a global perspective. Geneva: WHO Publication; 2008.

38. Lancet Global Mental Health Group, Chisholm D, Flisher AJ, Lund C, Patel V, Saxena $S$, et al. Scale up services for mental disorders: a call for action. Lancet. 2007;370(9594):1241-52.

\section{Publisher's Note}

Springer Nature remains neutral with regard to jurisdictional claims in published maps and institutional affiliations.

Ready to submit your research? Choose BMC and benefit from

- fast, convenient online submission

- thorough peer review by experienced researchers in your field

- rapid publication on acceptance

- support for research data, including large and complex data types

- gold Open Access which fosters wider collaboration and increased citations

- maximum visibility for your research: over $100 \mathrm{M}$ website views per year

At $\mathrm{BMC}$, research is always in progress.

Learn more biomedcentral.com/submission 